\title{
A atuação do supervisor de ensino da rede estadual de ensino de São Paulo: uma investigação sobre suas limitações para a inclusão de alunos com TEA
}

\author{
Osório Augusto de Souza Neto ${ }^{1}$
}

\author{
Estéfano Vizconde Veraszto ${ }^{2}$
}

\begin{abstract}
Resumo
Esta pesquisa, de cunho qualitativo, realizada mediante Análise Textual Discursiva, mostrou as limitações de atuação do Supervisor de Ensino da Rede Pública Estadual do Estado de São Paulo em questões pertinentes à oferta/matrícula no AEE (Atendimento Educacional Especializado) de alunos com TEA (Transtorno do Espectro do Autismo), gerando restrições e o cerceamento de direitos de uma educação plena aos alunos com a deficiência já apontada. Foi possível verificar que a emissão de pareceres para a oferta e matrícula de alunos com TEA no AEE se restringe somente para aqueles alunos que possuem diagnóstico clínico/ médico, em total descompasso com os referencias teóricos da área, bem como em relação às orientações técnicas do Ministério da Educação. Evidenciou-se ainda a necessidade de uma reavaliação de elementos normativos internos, pela Secretaria de Estado da Educação de São Paulo (SEE/SP), no tocante aos critérios para oferta e matrícula no AEE de alunos com TEA.
\end{abstract}

Palavras-chave: Supervisor de Ensino da Rede Pública Estadual de São Paulo. Alunos com TEA. Atendimento Educacional Especializado. Diagnóstico Clínico. Proteção dos Direitos da Pessoa com Transtorno do Espectro Autista.

\begin{abstract}
This qualitative research, carried out through Discursive Textual Analysis, showed the performance limitations of the State Public School Network Supervisor of the State of São Paulo, regarding the offer / registration in the SEA (Specialized Educational Assistance) of students with ASD (Autism Spectrum Disorder), resulting in restrictions and curtailing of the rights of a full education to the students with the deficiency mentioned above. It was possible to verify that the issuance of opinions regarding the offer and enrollment of students with ASD in the SEA is restricted only to those students who have clinical / medical diagnosis, in total disagreement with the theoretical references of the area, as well as in relation to the technical orientations of the Ministry of Education. It was also evidenced the need for a re-evaluation of internal normative elements, by the State Department of Education of São Paulo (SEE / SP), regarding the criteria for the offer and enrollment in the SEA of students with ASD.
\end{abstract}

Keywords: State Public School Network Supervisor of the State of São Paulo. Students with ASD. Specialized Educational Assistance. Clinical Diagnosis. Protection of the rights of people diagnosed with Autism Spectrum Disorder.

\footnotetext{
${ }^{1}$ Mestrando em Educação em Ciências e Matemática pela Universidade Federal de São Carlos (UFSCar) - Campus Araras. Professor de Matemática do Grupo COC. E-mail: osorionet2003@gmail.com

${ }^{2}$ Doutor em Educação Ciência e Tecnologia pela Universidade Estadual de Campinas (UNICAMP) É professor Adjunto da UFSCar e Coordenador do Programa de Pós-Graduação em Educação em Ciências e Matemática da UFSCar - Campus Araras. E-mail: estefanovv@gmail.com
} 
Introdução

A matrícula dos alunos Público Alvo da Educação Especial (PAEE) nas redes regulares de ensino, antes da proclamação da Declaração de Salamanca (BRASIL, 1994), construída na Conferência Mundial de Educação Especial na Espanha em 1984, bem como antes da promulgação da Lei de Diretrizes e Bases da Educação Nacional (BRASIL, 1996), era muito pequena mediante aquilo que se tem hoje. Em tais documentos, o primeiro deles na década de 1990, embora sem caráter normativo, foi o que permitiu a visibilidade da necessidade de uma educação pautada em ideais de equidade, fundamentada em princípios, políticas e práticas para inclusão de alunos com Necessidades Educacionais Especiais (NEE) nas redes regulares de Ensino. Após a promulgação de (BRASIL, 1996) que tornou obrigatória a matrícula de alunos a partir dos sete anos de idade é que houve, a partir de 2001, um aumento significativo das matrículas de alunos com NEE e alunos PAEE nas Redes Públicas de Ensino, desde quando um declínio da matrícula destes alunos nas Redes Privadas de Ensino. (BRASIL, 2007).

Dentro do contexto do presente estudo, especificamente sobre o Transtorno do Espectro do Autismo (TEA), até mesmo pelas dimensões do presente trabalho e ao que nele se busca, torna-se importante salientar que o TEA somente foi determinado como deficiência em 2012, através da Lei Federal n 10,764, de 27 de dezembro de 2012, que Instituiu a Política Nacional de Proteção dos Direitos da Pessoa com Transtorno do Espectro Autista (BRASIL, 2012), quando diz em seu artigo $1^{\circ}$ que:

[...]. $\S 1^{\circ}$ - Para os efeitos desta Lei, é considerada pessoa com transtorno do espectro autista aquela portadora de síndrome clínica caracterizada na forma dos seguintes incisos I ou II: I -deficiência persistente e clinicamente significativa da comunicação e da interação sociais, manifestada por defíciência marcada de comunicação verbal e não verbal usada para interação social; ausência de reciprocidade social; falência em desenvolver e manter relações apropriadas ao seu nível de desenvolvimento; II -padrões restritivos e repetitivos de comportamentos, interesses e atividades, manifestados por comportamentos motores ou verbais estereotipados ou por comportamentos sensoriais incomuns; excessiva aderência a rotinas e padrões de comportamento ritualizados; interesses restritos e fixos. [...]

O elemento normativo mencionado, bastante genérico para algumas questões, principalmente quanto ao discriminado no parágrafo único de seu artigo $3^{\circ}$, ao mencionar que os alunos com TEA, quando comprovada a necessidade, terão direito a acompanhante especializado em sala de aula. Com a finalidade de dirimir eventuais interpretações equivocadas, o elemento normativo que disciplina o assunto foi regulamentado, com norteamento dado pela Nota Técnica 24/2013(BRASIL, 2013), através do Decreto Federal no 8.368, de 2 de dezembro de 2014, que institui a Política Nacional de Proteção dos Direitos da Pessoa com Transtorno do Espectro Autista (BRASIL, 2014).

Ademais, em que pese (BRASIL, 2012), independentemente de regulamentação dado por (BRASIL, 2014b), a oferta de Atendimento Educacional Especializado (AEE) em salas de recursos multifuncionais (SRM) deve ser dado a todo aluno com deficiência, independentemente de laudo médico, conforme a Orientação quanto aos documentos comprobatórios de alunos com deficiência, transtornos globais do desenvolvimento e altas habilidades/ 
superdotação no Censo Escolar (BRASIL, 2014a), dado que o atendimento prestado pela escola tem natureza educacional, e não clínico (BRASIL,2014a).

É neste sentido que a Nota Técnica no 04 (BRASIL, 2014a, p.3) pontua que:

\begin{abstract}
Neste liame não se pode considerar imprescindível a apresentação de laudo médico (diagnóstico clínico) por parte do aluno com deficiência, transtornos globais do desenvolvimento ou altas habilidades/superdotação, uma vez que o AEE caracteriza-se por atendimento pedagógico e não clínico.[...] tornando-se o laudo médico, neste caso, um documento anexo ao Plano de AEE. Por isso, não se trata de documento obrigatório, mas, complementar, quando a escola julgar necessário. O importante é que o direito das pessoas com deficiência à educação não poderá ser cerceado pela exigência de laudo médico. A exigência de diagnóstico clínico [...], denotaria imposição de barreiras ao seu acesso aos sistemas de ensino, configurando-se em discriminação e cerceamento de direito.
\end{abstract}

Contudo, a matrícula de alunos PAEE no AEE atualmente, na Rede Pública de Ensino do Estado de São Paulo, não é cumprida conforme prevê os elementos normativos e orientativos federais vigentes, face ao que dispõe o atendimento educacional aos alunos públicoalvo da Educação Especial, na Rede Estadual de Ensino (SÃO PAULO, 2017).

É nesse contexto que São Paulo (2017, p.2) mostra que:
Artigo $5^{\circ}$ - Os pedidos de autorização para oferta de Atendimento Educacional Especializado - AEE, sob a forma de Sala de Recursos ou na modalidade itinerante, deverão comprovar a existência de demanda, e ser instruídos com: I - avaliação pedagógica, realizada por professor especializado, e psicológica do aluno, em caso de deficiência intelectual; II - laudo médico, no caso de deficiências auditiva/surdez, física, visual, surdo cegueira, transtorno do espectro autista e defíciência múltipla e múltipla sensorial; [...] Artigo $6^{\circ}$ - A autorização para oferta de Atendimento Educacional Especializado - AEE, sob a forma de Sala de Recursos, em unidade escolar, observados os requisitos/ documentos, previstos no artigo $5^{\circ}$, dar-se-á mediante processo autuado na Diretoria de Ensino e instruído, obrigatoriamente, com os seguintes documentos: [...] V -parecer do Supervisor de Ensino responsável pela unidade escolar.

Diante do contexto mencionado, e mediante o que postula o Decreto Estadual $\mathrm{n}^{\circ} 57.141$, de 18 de julho de 2011, que menciona as atribuições do Supervisor de Ensino da Rede Pública Estadual de São Paulo, principalmente como ator do processo educacional através de ações orientativas e sanativas“"...] na orientação e no acompanhamento do desenvolvimento de ações voltadas à melhoria da atuação docente e do desempenho dos alunos [...]"( SÃO PAULO, 2011, art. 72, d), o Supervisor de Ensino deve dar suporte à real inclusão dos alunos, de forma incondicional e sempre garantir melhorias no desempenhos dos estudantes.

Desta forma, o presente estudo buscará mostrar as limitações do trabalho do Supervisor de Ensino da Rede Pública de Ensino do Estado de São Paulo, mediante as imposições de elementos normativos estaduais vigentes, e que se apresentam contraditórios e ao avesso ao atual designer moderno da educação inclusiva, sobretudo aqueles que disciplinam o AEE para alunos com TEA. 


\section{Fundamentação teórica}

O assunto/temática do presente estudo ainda é novo, o que não abre um grande leque de opções para uma fundamentação teórica aprofundada e já enraizada pela academia. Contudo, o presente trabalho trará em seu bojo alguns referenciais teóricos generalistas em inclusão, uma vez que se vislumbrou, pelas pesquisas realizadas para a construção deste trabalho, em limitações de referenciais que possam permear a atuação do Supervisor de Ensino da Rede Pública Estadual de São Paulo envolvendo a questão principal deste trabalho.

Segundo Barbosa (2017, p.172):

Consequentemente, pelo menos em termo de orientações advindas do Governo Federal para os sistemas de educação, o laudo clínico não é obrigatório e, assim sendo, o professor de Educação Especial responsável pelas Salas de Recursos Multifuncionais (SRM), poderá propor um Plano de Atendimento Educacional Especializado para alunos com TEA, sem que estes tenham um laudo médico e/ou um código de doença.

Neste sentido, de forma bem clara e precisa, fica evidenciado pelas concepções apontadas em (BARBOSA, 2017), que a oferta de AEE para alunos com TEA sem laudo clínico se fundamenta em elementos orientativos de natureza Federal para o devido atendimento aos alunos PAEE com TEA em AEE, sem laudo médico. Para isso, aponta que os atendimentos em SRM devem ser pautadas nas percepções e orientações do Professor de Educação Especial (PEE).

Corrobora às ideias de Barbosa (2017), o prescrito por Bezerra (2017, p.17) quando aponta que:

\footnotetext{
Isto é, o laudo tem o poder de representar e criar representações sobre quem se refere, de legitimar pela máscara da imparcialidade a posição social inferior e desprestigiada que passa a ser ocupada por alguns dos jogadores em campo, direcionando assim as práticas escolares reprodutoras da exclusão na inclusão.
}

Dessa forma, restou evidenciado pelo primeiro autor mencionado o descarte de laudo médico para comprovar o TEA, apontando a oferta de AEE ao aluno com TEA, mesmo somente com indicativos apresentados por professor da SRM. Ressalte-se aqui que, independente de laudo médico, que a oferta e matricula do aluno com suspeitas de TEA no AEE não gera qualquer tipo de rotulação que poderá lhe trazer prejuízo futuro, vez que o atendimento dado ao aluno em SRM é sempre pedagógico, e nunca clínico.

Os referenciais teóricos mencionados sobre a temática são bastante recentes, e mesmo sem ser específicos sobre a questão principal objeto de estudo, já passaram pelo crivo da academia, de forma a ter maior visibilidade e credibilidade.

Nesse sentido, o presente trabalho será pautado, fundamentalmente, nos elementos normativos e orientativos das esferas federal (BRASIL, 2012, 2013, 2014a, 2014b) e estadual (SÃO PAULO, 2011,2017), bem como nos referenciais teóricos mencionados. 


\section{Procedimentos metodológicos}

Esta é uma pesquisa é de natureza analítica, que busca encontrar, dentre os elementos trazidos à análise, possíveis similaridades e/ou contradições entre os elementos apontados, como subsídio ao trabalho do Supervisor de Ensino frente à oferta e matrícula no AEE de alunos com TEA.

Neste sentido, uma análise feita de forma sistematizada sobre os elementos normativos e orientativos descritos na Tabela 01serárealizada mediante técnicas de Análise Textual Discursiva (MORAES; GALIAZZI, 2016).

Tabela 1 - Documentos e normativos e orientativos para o AEE de alunos com TEA

\begin{tabular}{|c|c|c|c|}
\hline $\begin{array}{l}\mathrm{N}^{0} \text { do } \\
\text { Documento }\end{array}$ & Elemento Analisado & Referência & Objetivo \\
\hline 01 & Lei $n^{\circ} 12.764 / 2012$ & (BRASIL, 2012) & $\begin{array}{c}\text { Instituir a Política Nacional de Proteção dos Direitos da } \\
\text { Pessoa com Transtorno do Espectro Autista; e alterar o } \\
\S 3^{\circ} \text { do art. } 98 \text { da Lei n }{ }^{\circ} 8.112 \text {, de } 11 \text { de dezembro de } \\
1990 .\end{array}$ \\
\hline 02 & Nota Técnica n²4/2013 & (BRASIL, 2013) & $\begin{array}{l}\text { Orientar os Sistemas de Ensino para a implementação } \\
\qquad \text { da Lei } n^{\circ} 12.764 / 2012 .\end{array}$ \\
\hline 03 & Decreto $n^{\circ} 8.368 / 2014$ & (BRASIL, 2014b) & $\begin{array}{l}\text { Regulamentar a Lei n }{ }^{\circ} 12.764 \text {, de } 27 \text { de dezembro de } \\
\text { 2012, que institui a Política Nacional de Proteção dos } \\
\text { Direitos da Pessoa com Transtorno do Espectro Autista. }\end{array}$ \\
\hline 04 & $\begin{array}{l}\text { Nota Técnica } \mathrm{n}^{\circ} \\
04 / 2014\end{array}$ & (BRASIL, 2014a) & $\begin{array}{c}\text { Orientar quanto aos documentos comprobatórios } \\
\text { de alunos com deficiência, transtornos globais do } \\
\text { desenvolvimento e altas habilidades/superdotação no } \\
\text { Censo Escolar. }\end{array}$ \\
\hline 05 & $\begin{array}{l}\text { Resolução SE n }{ }^{\circ} \\
68 / 2017\end{array}$ & $\begin{array}{l}\text { (SÃO PAULO, } \\
\text { 2017) }\end{array}$ & $\begin{array}{l}\text { Dispor sobre o atendimento educacional aos alunos, } \\
\text { público-alvo da Educação Especial, na rede estadual de } \\
\text { ensino }\end{array}$ \\
\hline
\end{tabular}

Fonte: Elaborado pelos autores

Os elementos da Tabela 1 formarão o corpus da nesta etapa de análise, relativamente à metodologia de Análise Textual Discursiva (MORAES; GALIAZZI, 2016; NETO; VERASZTO, 2018), na seguinte conformidade:

1. Unitarização: Se mostra mediante a fragmentação dos documentos na busca de elementos, intrínsecos e extrínsecos, ao estudo;

2. Relações: Categorização que envolve a relação entre os documentos analisados;

3. Captação do novo emergente: Mediante os resultados já apresentados, a compreensão da totalidade dos documentos analisados permitirá a elaboração de um metatexto, produto dos elementos apontados anteriormente, ressalvando aquilo já construído nas etapas anteriores; 
4. Processo auto organizado: A análise, mesmo que construída de forma fragmentada, poderá ser compreendida na íntegra, a partir de resultados finais elaborados/criados de forma criativa.

O software NVivo (2017) será utilizado para a categorização, à posteriori, das relações entre os documentos apontados na Tabela 01. "No caso do NVivo, existem ainda outros aspectos a serem definidos, antes de iniciar o trabalho com o software. Entre eles, a forma como os dados serão armazenados, se haverá ou não categorias predefinidas" (LAGE, 2011, p.204).

O software mencionado é uma ferramenta que auxilia o pesquisador nas pesquisas de cunho qualitativo, sempre de forma a tornar mais eficiente a organização e delineamento dos dados. Desta forma, é importante ressaltar que o NVivo (2017) não substitui, em nenhuma hipótese, o papel do pesquisador, mas tão somente torna o processo de avaliação, análise e conclusão sobre os dados da pesquisa, mais rápido do que uma compilação manual.

As Figuras 01 e 02 ilustram as palavras/termos que mais aparecem nos elementos analisados. As palavras centrais da figura e com maior tamanho de fonte representam aquelas com maior frequência de aparência nos documentos, enquanto aquelas que se mostram às margens e com menor tamanho de fonte, são aquelas que se apresentam no corpus da análise com menor frequência (NETO; VERASZTO, 2018).

Após, na pesquisa em tela realizou-se uma análise de clusters (Figura 03). Nesta análise, realizada através do Nvivo (2017) é analisado a similaridade entre palavras/termos contidos nos documentos analisados que consiste em uma técnica de

[...] classificação que objetiva agrupar dados de acordo com as similaridades entre eles. Agrupa um conjunto de dados heterogêneos, em grupos com homogeneidade, utilizando um critério fixado. Pode ainda ser descrito da seguinte forma: dado um conjunto de $\mathrm{n}$ indivíduos para os quais existe informação sobre a forma de p variáveis, o método agrupa os indivíduos em função da informação existente, de modo que os indivíduos de um grupo sejam tão semelhantes quanto possível e sempre mais semelhantes aos elementos do mesmo grupo, do que a elementos dos restantes grupos (BEM; GIACOMIN; WAISMANN, 2015, p.28).

A partir do explicitado, tem-se a os resultados e a discussão a seguir.

\section{Resultados e discussão}

A primeiro momento foi realizada uma contagem dos termos que mais aparecem nos documentos analisados. Importante ressaltar, que para maior clareza e sentido à análise, foram selecionadas para a Figura 01 e 02 palavras que mais aparecerem nos documentos analisados, com 6(seis) caracteres ou mais, com generalização para sinônimos e palavras no plural, de forma que ambas, plural e sinônimos, sejam contabilizados uma vez só. Dessa forma, o primeiro contato visual com a Figura 01 já permite saber qual é o assunto objeto de pesquisa, facilitando uma análise mais detalhada sobre o assunto da investigação.

Para esta pesquisa, tratando-se de uma investigação e análise de documentos atinentes à oferta de AEE para alunos com TEA sem diagnóstico clínico/médico, tomamos como corpus da análise pelo NVivo (2017) os 
elementos trazidos pela Tabela 01. A ideia central é verificar o que dizem tais documentos, sempre no sentido da atuação do Supervisor de Ensino(direta ou indiretamente) frente às questões que se aproximam ou se distanciam da oferta e matrícula no AEE para alunos com TEA sem diagnóstico clínico/médico.

Figura 1 - Nuvem de palavras dos documentos apresentados na Tabela 1

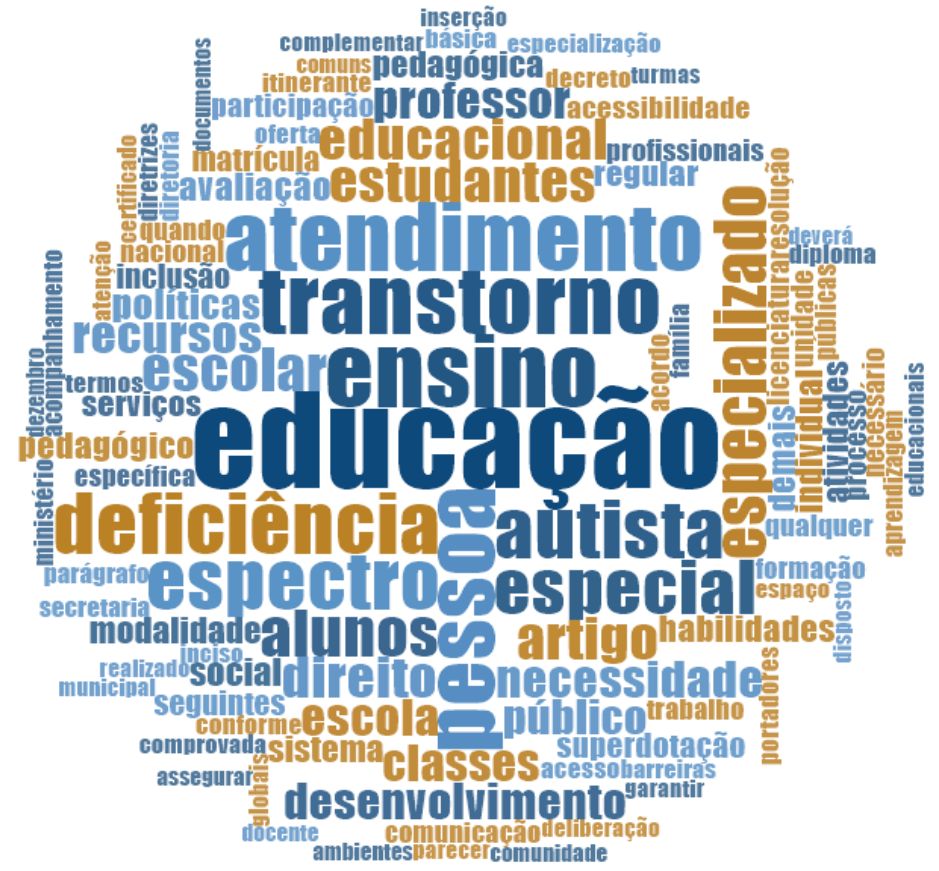

Fonte: NViv011@, 2017

Figura 2 - Contagem das 10 palavras mais frequentes nos documentos da Tabela 01

\begin{tabular}{|c|c|c|}
\hline Palavra & Contagem & Percentual Ponderado \\
\hline educação & 114 & 1,35 \\
\hline ensino & 81 & 0,96 \\
\hline pessoa & 76 & 0,90 \\
\hline transtorno & 76 & 0,90 \\
\hline atendimento & 65 & 0,89 \\
\hline deficiência & 67 & 0,79 \\
\hline autista & 64 & 0,76 \\
\hline espectro & 64 & 0,76 \\
\hline especial & 58 & 0,69 \\
\hline especializado & 52 & 0,62 \\
\hline
\end{tabular}

Fonte: Gráfico: Excel, 2018; Tabela :NViv011@, 2017

Mediante a análise das Figuras 01 e 02, verificou-se mediante a processo inicial de Análise Textual Discursiva (MORAES, GALIAZZI, 2016), a necessidade de garantias de uma educação especializada para alunos PAEE, assertivamente para aqueles com TEA, mediante a oferta e matrícula no AEE através de avaliação do aluno pelo 
PEE da Rede Pública Estadual de Ensino do Estado de São Paulo. Ressalte-se que durante a análise da Figura 01, dentre as 1000 palavras com maior frequência, o NVivo (2017)contabilizou a palavra “diagnóstico" em apenas 6 (seis) ocasiões, enquanto as palavras "médicos" e "clínico" não foram contabilizados nenhuma vez como alguma palavra das 1000 mais frequentes, o que nos remete à uma conclusão inicial acerca da ausência da necessidade de diagnóstico clínico ou médico para oferta e matrícula de alunos com TEA, corroborando com os estudos em questões similares da área (BARBOSA; BEZERRA, 2017).

Como já mencionado anteriormente, mediante a ausência de estudos específicos na questão apontada, ou seja, do papel do Supervisor de Ensino nas questões relativas à oferta e matrícula de alunos com TEA no AEE, o presente trabalho apresentou ênfase à uma análise exploratória e analítica dos dados presentes na Tabela 01 . A partir daí realizou-se uma análise de clusters com o software já mencionado. O resultado está evidenciado no dendograma apresentado na Figura 2.

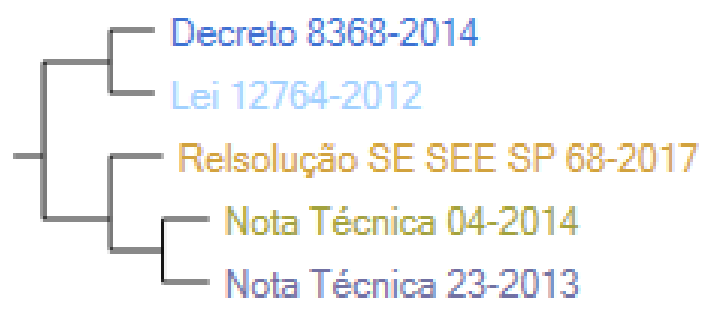

Figura 2 - Dendograma da análise de clusters da Tabela 01

Fonte: NViv011@, 2017

Através da metodologia de pesquisa já mencionada anteriormente, a partir da análise de clusters (Figura 2) foi possível uma categorização, à posteriori, que permitiu a construção de um metatexto inédito apontando 2 (duas) categorias dadas pelos itens a e b a seguir:

a. A primeira categoria, categorizada como Elementos Normativos, dada pelo agrupamento (Decreto 8368-2014+Lei 12764-2012) permite inferir que tais documentos, de cunho obrigatório para todos os Sistema de Ensino do território brasileiro, convergem para a obrigatoriedade do AEE para alunos com TEA.

b. A segunda categoria, categorizada como Elementos Orientativos, dada pelo segundo agrupamento (Nata Técnica 04-2014+Nota Técnica 23-2013+ Resolução SE SEE 68-2017) permite perceber, que contém elementos orientativos (Notas Técnicas) a todos os Sistemas de Ensino brasileiros. As notas técnicas corroboraram para a orientação e regulamentação da lei, através do decreto, ambos da primeira categoria.Já a Resolução SE SEE 68-2017, elementoque dispõe sobre o atendimento dos alunos PAEE no AEE no Sistema de Ensino Estadual do Estado de São Paulo, é elemento de caráter normativo interno, à medida que regulamenta somente, e tão somente, os atendimentos de AEE desuas escolas. Deste modo, se justifica, como documento de caráter obrigatório para cumprimento daqueles que atuam na Rede Estadual de Ensino do Estado de São Paulo. 
Diante do apontado nas duas categorias, torna-se muito evidente o descumprimento dos Elementos Normativos mencionados aqui, pela Secretaria de Estado de Educação do Estado de São Paulo (SEE/SP), já que se tratam de documentos de cunho obrigatório. O seu não cumprimento impossibilita uma atuação transformadora do Supervisor de Ensino, na Rede Estadual de Ensino, de forma a garantir uma educação de qualidade.

Torna-se importante ressaltar que os Elementos Normativos presentes na primeira categoria apresentada, bem como as Notas Técnicas mencionadas na segunda, não admitem, em nenhuma hipótese, uma interpretação que fundamente as limitações do Supervisor de Ensino apresentadas em (SÃO PAULO, 2017), dentro do contexto já mencionado.

Ademais, com a finalidade de demostrar, com um pouco mais de afinco e elementos sobre o descumprimento, pela SEE/SP, dos elementos já mencionados neste tópico, e que inviabilizam um trabalho eficiente do Supervisor de Ensino da Rede Estadual de Ensino de São Paulo, apresentaremos um, e apenas um, contraexemplo de conscientização sobre a necessidade de cumprimento do já estabelecido.

O governo de estado do Distrito Federal publicou, em 18 de fevereiro de 2014, a Lei no 5.310, que "Dispõe sobre a educação especial e o atendimento e acompanhamento integral aos estudantes que apresentem necessidades especiais nos diferentes níveis, etapas e modalidades de educação" (DISTRITO FEDERAL, 2014). Em seu art. $1^{\circ}$ mostra que:

\footnotetext{
Art. $1^{\circ}$ - Esta Lei dispõe sobre a educação especial e o atendimento e acompanhamento integral aos estudantes que apresentem necessidades especiais nos diferentes níveis, etapas e modalidades de educação. Parágrafo único. Para efeito desta Lei, estão contemplados os alunos atendidos pela Educação Especial (com deficiência, com transtornos globais do desenvolvimento e aqueles com altas habilidades ou superdotação), bem como os alunos com Transtorno do Déficit de Atenção e Hiperatividade - TDAH, Dislexia, Discalculia, Disortografia, Disgrafia, Dislalia, Transtorno de Conduta e Distúrbio do Processamento Auditivo (Central) - DPA(C).
}

Nesse contexto é notável a preocupação do legislador, mas não apenas com alunos PAEE, mas com os alunos que tenham dificuldade especial de aprendizagem (NEA), facilitando a atuação do Supervisor de Ensino daquele Estado para os processos de oferta e matrícula de alunos com TEA.

Para a normatização da Lei mencionada (DISTRITO FEDERAL, 2014), emerge, do Conselho de Educação do Distrito Federal, a Resolução CEDF no 01, de 12 de abril de 2017 que "Estabelece Normas para a Educação Especial no Sistema de Ensino do Distrito Federal e dá outras providências"(DISTRITO FEDERAL, 2017)e que apresenta em seus artigos $8^{\circ}, 9^{\circ}$ e 10 a seguinte redação:

\footnotetext{
Art. $8^{\circ}$ No ato da matrícula, é de responsabilidade dos pais ou responsáveis a apresentação de laudo médico ou relatório de avaliação diagnóstica, a fim de garantir precisão aos encaminhamentos pertinentes e necessários, inclusive a adequada enturmação do estudante. $\S 1^{\circ} \mathrm{A}$ ausência de laudo médico ou relatório de avaliação diagnóstica não se configura fator impeditivo de matrícula. $2^{\circ}$ Caso a identificação da necessidade de atendimento educacional especializado ocorra no curso de período letivo, compete à instituição educacional promover o chamamento da família, com vistas à implementação das disposições desta Resolução.Art. $9^{\circ} \mathrm{O}$ laudo médico ou o relatório de avaliação
} 
diagnóstica deve considerar:I - fatores ambientais, pessoais, psicológicos e socioemocionais; II - os impedimentos nas funções e nas estruturas corporais; III - a limitação no desempenho de atividades; IV - a restrição de participação, dentre outros aspectos que se julgar pertinente. Art. 10. A resposta diagnóstica oriunda das avaliações procedidas pelo professor e pela equipe pedagógica da instituição educacional norteará as ações pedagógicas e encaminhamentos a serem implementados, que poderá contar com a colaboração de outros profissionais das áreas de saúde, do trabalho, do serviço social, dentre outras.

Modo, muito transparente é a orientação de (DISTRITO FEDERAL, 2017) ao mencionar, por exemplo, no caput do art. $1^{\circ}$ que se trata de responsabilidade dos pais ou responsáveis a apresentação de laudo médico ou relatório de avaliação diagnóstica para os alunos desta Modalidade de Ensino. Deste modo, a resposta diagnóstica prescrita em seu artigo 10 é o suficiente para a matrícula do PAEE no AEE, o que corrobora com o entendimento de que o trabalho do Supervisor de Ensino, frente às ação de inclusão, oferta e matricula de alunos com TEA no AEE, naquele ente federado, são substancialmente melhores e mais eficientes do que na Secretaria de Estado da Educação de São Paulo.

Além, resta claro em (DISTRITO FEDERAL, 2017), no $§ 1^{\circ}$ de seu artigo $8^{\circ}$ que a ausência de laudo médico não é fator impeditivo para o atendimento do PAEE no AEE, o que inclue os alunos com TEA e, por consequência, uma atuação mais ampla e eficiente do Supervisor de Ensino naquele ente federativo. Resta esclarecido portanto, que as ações já mencionadas nesta investigação carecem, nada mais do que vontade política para permear elementos que agreguem valores à educação como um todo, corroborando, ao final, com uma atuação sem limitações técnicas veladas, ao Supervisor de Ensino, como ocorre no Estado de São Paulo.

Neste sentido, contrário ao proposto em (SÃO PAULO, 2017) dois grandes questionamentos surgem, de forma a mostrar, definitivamente, que tal elemento normativo, de natureza interna, se trata de uma articulação velada à atuação do Supervisor frente ao já apontado. A resposta à segunda questão responderá a primeira:

I) O que é mais importante para garantir, no contexto em análise, uma educação de qualidade?

II) Um laudo médico classificando um aluno como deficiente é, sob o ponto de vista educacional, mais ou menos importante do que os sinais de possível TEA, apresentados pelos alunos PAEE mencionados neste estudo?

\section{Considerações finais}

Através do exame dos elementos normativos, orientativos e dos referenciais teóricos trazidos à análise, foi possível concluir que os Supervisores de Ensino da Rede Estadual de São Paulo vivenciam, no tocante à oferta e matricula no AEE para alunos com TEA, um verdadeiro paradoxo.

Os estudos referenciais mencionados (BARBOSA; BEZERRA, 2017), pautados nas Notas Técnicas do Ministério da Educação $n^{\circ} 04$ e 23 (BRASIL,2013, 2014a) deixam claro a não obrigatoriedade de diagnóstico clínico/médico para a oferta e matrícula no AEE de alunos com TEA, bastando uma avaliação preliminar do PEE para sua oferta e matrícula no AEE. Por outro lado, a Secretaria de Estado da Educação de São Paulo, através de da Resolução SE no 68/2017 (SÃO PAULO, 2017) exige laudo/diagnóstico clínico/médico para a oferta e matrícula dos alunos com TEA no AEE, o que impede que o Supervisor de Ensino possa emitir parecer conclusivo 
para o atendimento deste PAEE específico no AEE quando não há a apresentação do diagnóstico mencionado na Resolução (SÃO PAULO, 2017), gerando um grande impasse quanto a qual seguir, a saber: Elementos Orientativos federais ou estaduais.

Desta forma, se evidenciou pelo presente estudo a necessidade de uma melhor avaliação das políticas públicas implementadas por atos administrativos internos, por parte da Secretaria de Estado da Educação do Estado de São Paulo, principalmente da Resolução SE nº 68/2017(SÃO PAULO, 2017) no tocante às exigências para a oferta de AEE, para alunos com TEA, de forma a permitir que o Supervisor de Ensino da Rede Estadual de São Paulo tenha uma participação efetiva nas garantias de aprendizagem dos alunos mencionados neste estudo.

\section{Referências}

BARBOSA, M., FUMES, N.L.F. Atividade docente e reflexões no atendimento educacional especializado para estudantes com transtorno do espectro autista. Revista Educação e Cultura Contemporânea, v.14, n.35, p.169-193, 2017. Disponível em: <http://periodicos.estacio.br/index.php/ reeduc/article/view/3232/47965084>. Acesso em: 12 dez. 2018.

BEM, J.S., GIACOMINI, N.M.R., WAISMANN, M. Utilização da técnica da análise de clusters ao emprego da indústria criativa entre 2000 e 2010: estudo da Região do Consinos, RS. Interações, Campo Grande, v. 16, n. 1, p. 27-41, 2015. Disponível em: $<$ http://www.scielo.br/pdf/inter/ v16n1/1518-7012-inter-16-01-0027.pdf>. Acesso em: 25 dez. 2018.

BEZERRA, G.F. A inclusão escolar de alunos com deficiência: uma leitura baseada em Pierre Bourdieu. Revista Brasileira de Educação, Naviraí, v. 22, n. 69, p.475-497, 2017. Disponível em: $<$ http://www.scielo.br/scielo.php?pid=S1413-24782017000200475\&script=sci_abstract\&tlng=pt $>$. Acesso em: 23 dez. 2018.

BRASIL. Declaração de Salamanca e linha de ação sobre necessidades educativas especiais. Brasília: UNESCO, 1994.

BRASIL. Ministério de Educação. LDB - Lei no 9394, de 20 de dezembro de 1996. Estabelece as diretrizes e bases da Educação Nacional. Brasília: MEC, 1996.

BRASIL. Política Nacional de Educação Especial na Perspectiva da Educação Inclusiva. Portaria Ministerial $n^{\circ}$ 555, de 5 de junho de 2007, prorrogada pela Portaria $n^{\circ}$ 948, de 09 de outubro de 2007. Ministério da Educação, 2007. Disponível em:<http://peei.mec.gov.br/arquivos/politica_nacional_ educacao_especial.pdf $>$. Acesso em: 25 dez. 2018.

BRASIL. Lei no 12.764, de 27 de dezembro de 2012. Institui a Política Nacional de Proteção dos Direitos da Pessoa com Transtorno do Espectro Autista; e altera o $\$ 3^{\circ}$ do art. 98 da Lei $\mathbf{n}^{\circ} 8.112$, de 11 de dezembro de 1990. Diário Oficial da República Federativa do Brasil, Brasília, DF, 2012. 
BRASIL. NOTA TÉCNICA No 24 / 2013 / MEC / SECADI / DPEE.Orientação aos Sistemas de Ensino para a implementação da Lei no ${ }^{12.764 / 2012}$. Ministério da Educação. Secretaria de Educação Continuada, Alfabetização, Diversidade e Inclusão Diretoria de Políticas de Educação Especial. Diário Oficial da República Federativa do Brasil, Brasília, DF, 2013.

BRASIL. NOTA TÉCNICA Nº 04 / 2014 / MEC / SECADI / DPEE.Orientação quanto a documentos comprobatórios de alunos com deficiência, transtornos globais do desenvolvimento e altas habilidades/superdotação no Censo Escolar. Ministério da Educação. Secretaria de Educação Continuada, Alfabetização, Diversidade e Inclusão Diretoria de Políticas de Educação Especial. Diário Oficial da República Federativa do Brasil, Brasília, DF, 2014a.

BRASIL. Decreto n.8.368, de 2 de dezembro de 2014. Regulamenta a Lei no 12.764, de 27 de dezembro de 2012, que institui a Política Nacional de Proteção dos Direitos da Pessoa com Transtorno do Espectro Autista.Diário Oficial da República Federativa do Brasil, Brasília, DF, $2014 b$.

LAGE, M.C. Utilização do software NVivo em pesquisa qualitativa: uma experiência em EaD. ETD Educação Temática. Digital, Campinas, v.12, n.esp., p.198-226, 2011.

DISTRITO FEDERAL. Lei $\mathrm{n}^{0} 5.310$, de 18 de fevereiro de 2014. Dispõe sobre a educação especial e o atendimento e acompanhamento integral aos estudantes que apresentem necessidades especiais nos diferentes níveis, etapas e modalidades de educação. Diário Oficial do Distrito Federal, 2014. Disponível em: <www.sinprodf.org.br/wp-content/uploads/2014/03/lei-nº-5.310_do-dia-18.02.14. pdf $>$ Acesso em 09 jan. 2019.

DISTRITO FEDERAL. Resolução no 01, de 14 de abril de 2017. Estabelece Normas para a Educação Especial no Sistema de Ensino do Distrito Federal e dá outras providências. Disponível em: <http://www.tc.df.gov.br/SINJ/Norma/ba162118673c45408d71e93d0f27a848/ Resolu_o_1_28_03_2017.html >. Acesso em: 09 jan. 2019.

MORAES, R.; GALIAZZI, M.C. Análise Textual Discursiva. 3.ed. Ijuí: Ed. Unijuí, 264p. 2016.

SÃO PAULO. Decreto n ${ }^{\circ}$ 57.141, de 18 de julho de 2011.Reorganiza a Secretaria da Educação e dá providências. Assembleia Legislativa do estado de São Paulo, 2011

SÃO PAULO. Resolução SE 68, de 12 de dezembro de 2017. Dispõe sobre o atendimento educacional aos alunos, público-alvo da Educação Especial, na rede estadual de ensino. Secretaria de Estado da Educação, São Paulo, 2017. Disponível em: <http://siau.edunet.sp.gov.br/ ItemLise/arquivos/68_17.HTM?Time=09/01/2019\%2015:47:54>. Acesso em: 25 dez. 2018.

SOUZA NETO, O.A.S.; VERASZTO, E.V. Formação de professores de ciências da natureza na perspectiva da educação inclusiva: um estudo de trabalhos realizados na UFSCAR Campus Araras. IV Congresso Nacional de Formação de Professores e XIV Congresso Estadual Paulista sobre Formação de Educadores, 2018, Águas de Lindóia. Disponível em <https://www.researchgate.net/ publication/329041152_Formacao_de_professores_de_ciencias_da_natureza_na_perspectiva_da_ educacao_inclusiva_um_estudo_de_trabalhos_realizados_na_UFSCAR_Campus_Araras $>$. Acesso em: 25 dez. 2018.

Recebido em: 15/01/2019.

Aprovado em: 13/06/2019 